\title{
Commentary: The audacity of hope
}

\author{
Brendon M. Stiles, MD
}

Please forgive me for stealing a title from former President Obama. But, after reading Caleb Matthews' compelling Young Surgeon's Note, ${ }^{1}$ I believe that some hope and audacity are called for. It is a piece that all cardiothoracic surgeons should read, experienced surgeons and trainees alike. In the article, Caleb describes his personal journey of being diagnosed and treated for lung cancer. He focuses on his approach of "realistic hopefulness" to deal with the overwhelming negative odds of his initial diagnosis of stage IIIB small cell lung cancer. The title of his work is derived from the sobering statistics of the reported survival for similar patients: $33 \%$ one-year survival, $0 \%$ five-year survival, and 9-month median survival.

Like Paul Kalanithi's book, When Breath Becomes Air, ${ }^{2}$ Caleb's story is strikingly painful, but beautifully told. It touches on the facts and technicalities of lung cancer, but also on the less well-defined and more mysterious aspects of cancer such as the mind-body connection, overcoming mental barriers, and perhaps most important, on hope. In the article, Caleb quotes another surgeon who claimed that "The concept of hope is elusive as we live in a datadriven world." I agree with this assessment of the current state of affairs, but like Caleb I think that it is a point worth pushing back on for our patients with cancer. Although I understand that patients can sometimes be led to have false expectations, I strongly dispute the concept of "false hope." Hope is defined by Merriam-Webster as "to cherish a desire with anticipation; to want something to happen or be true." If a patient has hope, nothing about it can therefore be false. Yes, as Caleb cites, patients overwhelmingly want to be informed about their disease and want full disclosure regarding their chances of survival, whether related to a

From the Department of Cardiothoracic Surgery, Weill Cornell Medicine, New York-Presbyterian Hospital, New York, NY.

Disclosures: Dr Stiles reports consulting/speaker fees from AstraZeneca, Pfizer, Ribon Therapeutics, Gala Therapeutics, WebMD, and Medtronic, and is on the Board of the Lung Cancer Research Foundation. The spouse of Dr Stiles receives salary/stock from Pfizer and PPD.

Received for publication Jan 27, 2020; accepted for publication Feb 6, 2020; available ahead of print Feb 14, 2020.

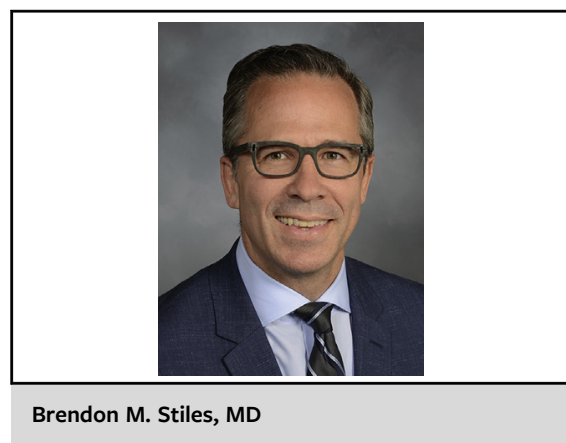

CENTRAL MESSAGE

Although it is important to honestly discuss prognosis with our patients, it is just as important to provide them with hope.

cancer diagnosis or to cardiovascular disease. But aren't we also obliged as physicians to provide comfort and hope? To deny that role would be a gross dereliction of our duty as doctors and would leave us as simple technicians, bound to data and didactic discussions of statistics. Caleb refuses to let the numbers define his own journey with lung cancer. And he correctly points out that we surgeons too often condemn our patients to those aggregated numbers and to binary outcomes. What patient would not lose hope upon hearing that he or she has zero chance of 5-year survival? Instead, Caleb argues for a nuanced and personalized description of data when speaking with patients. His perspective is powerful and worth considering. As Caleb suggests, we should never leave our patients "with the impression that the entirety of their life is defined by a set of numbers." Rather, we should leave them with hope, no matter how audacious.

\section{Reference}

1. Matthews C. Thirty-three, zero, nine. J Thorac Cardiovasc Surg. 2020;160:871-5. 2. Kalanithi P. When Breath Becomes Air. 1st ed. New York: Random House; 2016.
Address for reprints: Brendon M. Stiles, MD, Department of Cardiothoracic Surgery, Weill Cornell Medicine, New York-Presbyterian Hospital, 525 East 68th St, Greenberg Pavilion, M404, New York, NY 10065 (E-mail: Brs9035@ med.cornell.edu).

J Thorac Cardiovasc Surg 2020;160:876

$0022-5223 / \$ 36.00$

Copyright (C) 2020 by The American Association for Thoracic Surgery

https://doi.org/10.1016/j.jtcvs.2020.02.010 